\title{
ВЕРОЯТНОСТНАЯ ОЦЕНКА РИСКА ВОЗНИКНОВЕНИЯ АВАРИЙ НА БЕТОННЫХ ГРАВИТАЦИОННЫХ ПЛОТИНАХ НА СКАЛЬНОМ ОСНОВАНИИ
}

Ассист. Е.А. Балабай

\section{ІМОВІРНІСНА ОЦІНКА РИЗИКУ ВИНИКНЕННЯ АВАРІЙ НА БЕТОННИХ ГРАВІТАЦІЙНИХ ГРЕБЛЯХ НА СКЕЛЬНІЙ ОСНОВІ}

Асист. О.О. Балабай

\section{PROBABILISTIC RISK ASSESSMENT OF ACCIDENT AT CONCRETE GRAVITY DAM ON ROCK FOUNDATION}

\section{Assistant O.O. Balabai}

Метою роботи є розроблення способу імовірнісної оцінки ризику виникнення аварії на високих бетонних гравітаційних греблях. Об'єктивна оиінка надійності бетонних гравітаційних гребель може бути отримана імовірнісними методами сучасної теорії надійності. Запропоновано методику, щзо дозволяе виконати імовірнісну оиінку ризику виникнення аварій на бетонних гравітаційних греблях на скельній основі. 

aваріi.

Ключові слова: бетонна гребля, імовірнісна оиінка, аварії, скельна основа, ризик виникнення

Целью работь является разработка способа вероятностной оиенки риска возникновения аварии на высоких бетонных гравитационных плотинах. Обьективная оиенка надёжности бетонных гравитационных плотин может быть получена вероятностными методами современной теории надёжности. Предложена методика, позволяющая выполнить вероятностную оченку риска возникновения аварий на бетонных гравитационных плотинах на скальном основании.

Ключевые слова: бетонная плотина, вероятностная оценка, аварии, скальное основание, риск возникновения аварии.

The aim is to provide a method for probabilistic assessment of the risk of accidents on the high concrete gravity dam. An objective assessment of the reliability of concrete gravity dams can be obtained by probabilistic methods of the modern theory of reliability. Determination of the risk of an accident at gravity concrete dams on the bedrock was carried out by the example of the Great Ethiopian renaissance dam energy. All the original data provided by PJSC "Ukrhydroproject". Calculations are performed for the basic and special combinations of loads and impacts. Accidents on concrete gravity dams can be caused due to the ultimate state of the first group. The calculation is performed by the Monte Carlo (statistical tests). The technique, which allows to perform probabilistic risk assessment of accidents on concrete gravity dam on rock foundation.

Keywords: concrete dam, a probabilistic assessment, accident, bedrock, the risk of an accident.

\begin{abstract}
Введение. Для оценки надежности бетонных гравитационных плотин используется два подхода. Первый традиционный детерменистический по форме подход основан на методе предельных состояний. Согласно этому методу учёт случайных нагрузок и воздействий, показателей свойств материалов и грунтов, расчётных сроков эксплуатации сооружений, а также условий их работы выполняется на основе системы нормативных коэффициентов [1-2]. Метод предельных состояний не позволяет получить обьективную оценку надёжности бетонных гравитационных плотин. Это связано с тем, что значения нормативных коэффициентов не всегда являются обьективными и носят условный характер.

Второй подход основан на использовании вероятностных методов оценки надёжности бетонных гравитационных плотин [3].

Постановка проблемы в общем виде и ее связь с важными научными и практическими задачами

Определение цели и задачи
\end{abstract} исследования. Нормативный документ [4] регламентирует необходимость оценки риска возникновения аварий на гидротехнических сооружениях. Поэтому актуальной проблемой является разработка вероятностного способа оценки риска возникновений аварий на бетонных гравитационных плотинах на скальном основании.

Аварии на бетонных гравитационных плотинах возникают вследствие достижения предельного состояния, связанного с потерей устойчивости плотины против сдвига $P_{c}$, с исчерпанием прочности бетона тела плотины на сжатие $P_{b}$, с превышением предельной глубины зоны растяжения в горизонтальных сечениях тела плотины у верховой грани и в сечении по контакту плотины с основанием $P_{o}$, c потерей устойчивости плотины против опрокидывания $P_{\mu}$, с исчерпанием прочности контактного сечения $P_{p}[5,6]$. Одной из главных проблем при вероятносной оценке является получение достоверной информации об исходных данных случайных величин, которые характеризуют природные факторы. Поэтому актуальной задачей является разработка вероятностного способа оценки риска возникновений аварий на бетонных гравитационных плотинах на скальном основании.

Основная часть исследования. Определение риска возникновения аварии на бетонных гравитационныхых плотинах на скальном основании выполнялось на примере Великой энергетической плотины Эфиопского возрождения. Все исходные данные 
предоставлены ПАО «Укргидропроект», г. Харьков.

Строительство гидроузла Великой энергетической плотины Эфиопского возрождения мощностью 6 ГВт ведётся на р. Голубой Нил в Эфиопии. Высота плотины 142,00 м, ширина по основанию 109,60 м, общая длина 1783 м. Низовая грань плотины ступенчатая с заложением откосов 0,8. Для сообщения сооружений правого берега с левым по гребню бетонной плотины предусмотрена автодорога шириной 4,5 м. Основанием плотины служат скальные коренные породы (гнейсы). Основная часть плотины и напорная грань выполняются из вибрированного бетона $\mathrm{RCC}$, который также укладывается в основание плотины. Вдоль верховой грани плотины предусмотрена система дренажа в виде вертикальных скважин диаметром 130 мм, которые имеют выход в смотровые галереи. Расстояние между осями скважин 3,00 м. Расстояние от оси дренажных скважин до напорной грани плотины изменяется по высоте плотины от 2,0 до 7,3 м в зависимости от напора. Вдоль верховой грани плотины за слоем вибрированного бетона предусмотрены горизонтальные смотровые галереи на отметках $+614,500 \mathrm{M},+573,600 \mathrm{M},+554,850 \mathrm{M},+525,000 \mathrm{M}$, $+520,000$ м, $+506,000$ м. В галереях размещены системы для отвода фильтрационных вод в нижний бьеф. Через тело плотины проходит транспортно-коммуникационная галерея, которая соединяет правую и левую части станционной плотины.

Физико-механические и фильтрационные свойства скальных грунтов составлены по данным обьектов-аналогов и по данным изысканий фирмы «Salini», Италия.

Высота наносов определена в соответствии с работами $[7,8]$ и составила 50 м. Удельный вес наносов, насыщенных водой, $13 \kappa \mathrm{H} / \mathrm{m}^{3}$.

В районе строительства летом преобладают Индийские муссоны, а зимой Аравийские пассаты. Средняя многолетняя скорость ветра в районе строительства ГЭС 2 м/с, в зимние месяцы 1,6-1,9 м/с, в летний период до 2,5 м/с.

Удельный вес и характеристики укатанного бетона (см. рисунок):

- цилиндрическая прочность на сжатие в зоне $1 \mathrm{f}_{\mathrm{ck}}>12$ МПа (от отметки 503 до отметки 515 м);
- цилиндрическая прочность на сжатие в зоне $2 \mathrm{f}_{\mathrm{ck}}>10 \mathrm{MПа} \mathrm{(от} \mathrm{отметки} 515$ до отметки 565 м);

- цилиндрическая прочность на сжатие в зоне $3 \mathrm{f}_{\mathrm{ck}}>8 \mathrm{MПа} \mathrm{(от} \mathrm{отметки} 565$ до отметки $645 \mathrm{M})$.

Характеристики грунта скального основания: модуль Юнга - 10 ГПа; коэффициент Пуассона - 0,15; удельный вес 23,5 кН/м 3 ; удельное сцепление для поверхности сдвига по контакту бетон-скала - 300 кПа; угол внутреннего трения для поверхности сдвига по контакту бетон-скала - 50 град.

На рисунке показан разрез глухой бетонной гравитационной плотины Великой энергетической плотины Эфиопского возрождения.

Надёжность бетонной гравитационной плотины на скальном основании согласно действующим нормам проектирования определяется по двум группам предельных состояний $[1-2,4]$.

Расчеты выполняются для основного и особого сочетания нагрузок и воздействий. Аварии на бетонных гравитационных плотинах могут быть вызваны из-за достижения предельного состояния первой группы [3].

Основными этапами определения вероятности достижения предельного состояния бетонной гравитационной плотины являются [4]:

1. Построение уравнения связи между входными (нагрузки и воздействия на плотину, свойства материалов и основания) и выходными параметрами (результаты расчётов).

2. Подготовка входных параметров для расчёта в соответствии с принятым уравнением связи и распределением входных параметров на вероятностные и детерменистические.

3. Определение вероятностных характеристик входных параметров.

4. Вероятностная оценка достижения предельного состояния бетонной гравитационной плотины на основании решения задачи системной теории надёжности. Для решения этой задачи использовался метод статистических испытаний (Монте-Карло), который представляет собой численный метод решения математических задач на основании моделирования случайных величин.

5. Комплексная вероятностная оценка достижения какого-либо предельного состояния бетонной гравитационной плотины. 


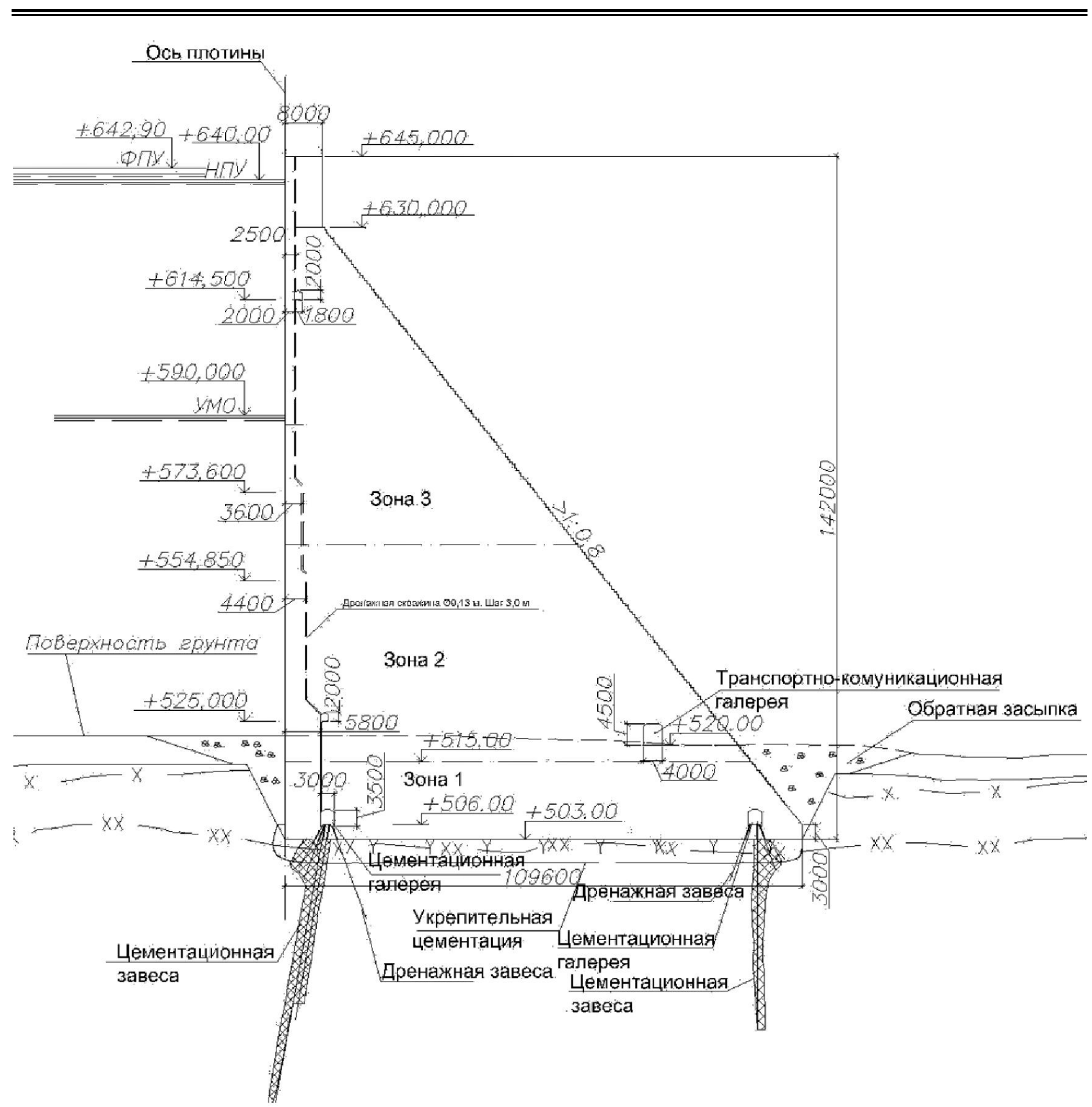

Рис. Разрез глухой бетонной гравитационной плотины Великой энергетической плотины Эфиопского возрождения

Оценка надёжности выполнена детерменистическим методом, в результате получены коэффициенты устойчивости против сдвига $k_{c}$, против опрокидывания $k_{o}$, потери прочности бетона на сжатие $k_{m}$. Например, для первого расчётного случая $k_{c}=1,61 ; k_{o}=2,68$; $k_{m}=2,35$. Для второго расчётного случая $k_{c}=1,54 ; k_{o}=2,8 ; k_{m}=2,0$. Для третьего расчётного случая $k_{c}=1,46 ; k_{o}=1,6 ; k_{m}=1,6$.

Далее выполняется расчёт по методу Монте-Карло (статистических испытаний). При этом производится необходимое колличество $\mathrm{N}$ статистических испытаний. Алгоритм расчетов при каждом статистическом испытании $\mathrm{j}$ $(\mathrm{j}=1,2, \ldots, \mathrm{N})$ следующий:

1. Для каждой из входящих случайных величин по номеру $i \quad(i=1,2, \ldots, \quad \mathrm{N})$ задаём равномерно распределённую в интервале от 0 до 1 случайную вероятность $P_{\mathrm{i}, \mathrm{j}}$.

2. По полученным значениям $P_{i, j}$, используя функции распределения, вычисляем 
значения аргументов $X_{i, j}$ каждой из случайных величин.

3. По известным значениям $X_{i, j}$ в соответствии с уравнением связи вычисляем значения совокупного фактора $Y_{j}$.

4. Проверяем выполнение условия достижения предельного состояния по полученным значениям совокупного фактора.

5. После выполнения всех $N$ испытаний вычисляем значение вероятности достижения предельного состояния $P_{u}$ как отношение числа испытаний $N_{j}$, когда условие наступления предельного состояния было достигнуто, к числу всех испытаний $N$.

При оценке надёжности гидротехнических сооружений должны учитываться нагрузки и воздействия, которые регламентируются действующими нормами проектирования [2]. Нагрузки и воздействия на бетонные гравитационные плотины принимаются в разнообразных, но возможных сочетаниях.

Детерминистическими

величинами приняты геометрические характеристики плотины; плотность бетона; плотность воды; вес моста; полезная нагрузка.

Вероятностными величинами приняты нагрузка от действия ветра; отметка уровня воды со стороны верхнего бьефа; средняя глубина уровня воды в зависимости от расчетного уровня; прочностные характеристики бетона; длина разгона волны; высота ветрового нагона; средняя высота волны; средний период волны; средняя длина волны; высота волны $1 \%$ обеспеченности в системе волн $1 \%$; сила горизонтального волнового давления; собственный вес секции плотины; сила гидростатического давления; сила фильтрационного противодавления; сила давления наносов; инерционная сейсмическая нагрузка; сейсмическое гидродинамическое давление воды; сейсмическое давление наносов; характеристики скального грунта.

По полученным значениям вероятности возникновения аварии определяем обобщенный риск возникновения аварии на бетонной гравитационной плотине как для системы с последовательным соединением элементов (вероятность события, которое находится в безотказной работе системы, равно вероятности пересечения событий, которые находятся в безотказной работе каждого из элементов). Предполагается, что наступление хотя бы одного предельного состояния приводит к утрате надёжности бетонной плотины. Риск возникновения отказа этой системы определяется по следующей формуле [9]:

$$
P:=1-(1-p c r)^{\frac{1}{T}}
$$

где $p c r$ - вероятность аварии на плотине вследствие реализации событий, соответствующих рассмотренным предельным состояниям;

$T$ - расчётный срок службы плотины, $\mathrm{T}=100$ лет.

Выводы из исследования и перспективы, дальнейшее развитие в данном направлении. Результаты расчётов для класса сооружения СС3:

1. Ежегодная вероятность достижения предельного состояния, связанного с потерей устойчивости плотины против сдвига, $P_{c}=5,9 \cdot 10^{-5} 1 /$ год.

2. Ежегодная вероятность достижения предельного состояния, связанного с исчерпанием прочности бетона тела плотины на сжатие, $P_{b}=1,1 \cdot 10^{-3} 1 /$ год.

3. Ежегодная вероятность достижения предельного состояния, связанного с превышением предельной глубины зоны растяжения в горизонтальных сечениях тела плотины у верховой грани и в сечении по контакту плотины с основанием, $P_{o}=1,1 \cdot 10^{-3} 1 /$ год.

4. Ежегодная вероятность достижения предельного состояния, связанного с потерей устойчивости плотины против опрокидывания, $P_{м}=1,9 \cdot 10^{-4} 1 /$ год.

5. Ежегодная вероятность достижения предельного состояния, связанного с исчерпанием прочности контактного сечения, $P_{p}=8,0 \cdot 10^{-6} 1 /$ год.

6. Ежегодный обобщённый риск возникновения аварий на плотине, $P=1,3 \cdot 10^{-5} 1 /$ год.

7. Обобщённый риск возникновения аварий на плотине за весь срок службы, $P=1,3 \cdot 10^{-3}$.

8. Ежегодная допустимая вероятность аварий на ГТС составляет $5 \cdot 10^{-5} 1 /$ год.

Анализ полученных результатов показывает, что большое влияние на обобщённый риск возникновения аварий на плотине оказывают риск, связаный с потерей устойчивости плотины против опрокидывания $P_{м}$, риск, связанный с превышением прочности 


\section{Будівельні матеріали, конструкції та споруди}

бетона на сжатие $P_{b}$, и риск, связанный с превышением предельной глубины зоны растяжения в горизонтальных сечениях тела плотины у верховой грани и в сечении по контакту плотины с основанием $P_{o}$.

При сравненнии допустимой вероятности возникновения аварий с полученной по алгоритму, представленном в данной работе, очевидно, что полученная вероятность меньше, чем допустимая.
Также определено необходимое количество статистических испытаний для достижения довольно узкого доверительного интервала, которое составило $1,22 \cdot 10^{6}$.

Данная методика может быть использована при расчёте надёжности бетонных гравитационных плотин на скальном основании.

\section{Список использованных источников}

1986. $-40 \mathrm{c}$

1. СНиП 2.06.06-85. Плотины бетонные и железобетонные [Текст]. - М.: Госстрой СССР,

2. СНиП 2.06.04-82*. Нагрузки и воздействия на гидротехнические сооружения [Текст]. - М.: Госстрой СССР, 1988. -36 с.

3. Вайнберг, А.И. Надежность и безопасность гидротехнических сооружений. Избранные проблемы [Текст] / А.И. Вайнберг. - Харьков: Издательство «Тяжпромавтоматика», 2008. - 304 с.

4. ДБН В.2.4-3:2010. Гідротехнічні споруди. Основні положення [Текст]. - К.: Мінрегіонбуд України, 2010. - 37 с.

5. ICOLD. Dam failures - Statistical Analysis [Text] // Bulletin/ - 1995. - № 99. -75 p.

6. Blind H. The Safety of Dams [Text] // Int. Water Power and Dam construction. - 1983. - Vol. 35. - № 5. - P. 17-21.

7. Мозговий, А.О. Умови формування замулення водосховищ річкових гідровузлів / А.О. Мозговий, О.О. Балабай [Електронний ресурс]: Матеріали VI міжнар. наук.-техн. інтернет конф. ХНУМГ ім. О.М. Бекетова. - Харків, 2014. - Режим доступу: http://eprints.kname.edu.ua/37509/.

8. Шамов, Г.И. Заиление водохранилищ [Текст] / Г.И. Шамов. - М.-Л.: Гидрометеоиздат, 1939. - 139 c.

9. Ржаницын, А.Р. Теория расчета строительных конструкций на надёжность [Текст] / А.Р. Ржаницын. - М.: Стройиздат, 1978. - 239 с.

Рецензент д-р техн. наук, профессор А.И. Вайнберг

Балабай Олена Олександрівна, асистент кафедри гідротехнічного будівництва Харківського національного університету будівництва і архітектури. Тел. (057) 706-18-99. E-mail: balabai.olena@gmail.com.

Balabai Elena assistant of the Department of hydraulic engineering of Kharkiv National University of Construction and Architecture. Phone: (057) 706-18-99. E-mail: balabai.olena@gmail.com.

Стаття прийнята 09.11.2015 p. 